\title{
QUANTIFICAÇÃO DE MATERIAL COMBUSTÍVEL NO SUB-BOSQUE DE UM POVOAMENTO DE Platanus $x$ acerifolia
}

\author{
Lucas Scheidt da Rosa ${ }^{1}$ \\ Mauro Valdir Schumacher ${ }^{2}$ \\ Flávio Hoelscher ${ }^{3}$ \\ Jeison Tiago Alflen ${ }^{3}$ \\ Luciano Volenhaupt Pereira ${ }^{3}$ \\ Mariana Grassi $\mathrm{Noya}^{4}$
}

\begin{abstract}
RESUMO
O plátano (Platanus x acerifolia) tem despertado a atenção do setor moveleiro, em virtude das propriedades elásticas da madeira. Este trabalho teve por objetivo quantificar o material combustível existente no sub-bosque de um povoamento de plátano com 4,5 anos de idade, instalado em solo hidromórfico, em Santa Maria, RS. Em nove unidades amostrais, com $4 \mathrm{~m}^{2}$ cada, a biomassa combustível foi dividida em três classes de diâmetro $(0,25$; 1,$0 ; 3,0$ polegadas) com uso de gabarito. Cada classe foi pesada e teve uma amostra coletada e seca para determinação do peso seco total por hectare $\left(\mathrm{em} \mathrm{Mg} \mathrm{ha}^{-1}\right)$. Não foram encontrados exemplares com diâmetro superior a 1,0 polegada. Os diâmetros até 0,25 e até 1,0 polegada corresponderam, respectivamente, a $85 \%(8,42$ mg.h $\left.{ }^{-1}\right)$ e $15 \%\left(1,52 \mathrm{mg}^{-h^{-1}}\right)$ do total de biomassa no sub-bosque do povoamento. Os valores apresentaram-se relativamente baixos, provavelmente devido ao elevado grau de hidromorfia do solo na área.

Palavras-chave: Plátano, proteção florestal, incêndio florestal, biomassa.
\end{abstract}

\section{QUANTIFICATION OF COMBUSTIBLE MATERIAL IN THE SUB-FOREST OF A Platanus $x$ acerifolia SETTLEMENT}

\begin{abstract}
The plane tree (Platanus $x$ acerifolia) has been interesting for the furniture section, because of the elastic properties of the wood. This work had as objective to quantify the existent combustible material in the sub-forest of a 4,5 years old plane tree settlement, installed in hydromorfic soil, in Santa Maria, RS. In nine samples units, with $4 \mathrm{~m}^{2}$ each, the combustible biomass was divided in three diameter classes $(0,25 ; 1,0 ; 3,0$ inches) with form use. Each class was weight and the samples were collected for the determination of the total dry weight in an hectare (mg.ha $\left.{ }^{-1}\right)$, individuals with a diameter superior to 1,0 inch weren't find. The diameters up to 0,25 and up to 1,0 inch they corresponded, respectively, to $85 \%\left(8,42 \mathrm{mg} \cdot \mathrm{ha}^{-1}\right)$ and $15 \%\left(1,52 \mathrm{mg} \cdot \mathrm{ha}^{-1}\right)$ of the total biomass in the sub-forest of the settlement. The values seemed to be relatively low, probably due to the hydromorfic level of the soil in the studied area.

Key-words: Plane tree, forest protection, forest fire, biomass
\end{abstract}

\section{INTRODUÇÃO}

Existe atualmente no Brasil uma área reflorestada de aproximadamente 6.000 .000 de ha, constituída em sua quase totalidade por plantações de Eucalyptus spp e Pinus spp, com uma participação mínima de outras espécies exóticas e também nativas, como Araucaria angustifolia e Mimosa scabrella. Como as florestas plantadas são mais suscetíveis à incidência do fogo do que as naturais, as áreas reflorestadas no país têm convivido sob a ameaça, às vezes tornada realidade, de ocorrência periódica de incêndios (Soares, 1994).

Soares apud Santana et al. (2001), afirma que em uma floresta existe sempre grande quantidade de material combustível, por isso a estimativa desse material combustível é fator importante em planos de prevenção e controle de incêndios, especialmente em programas de queima controlada.

\footnotetext{
${ }^{1}$ Mestrando em Engenharia Florestal no PPGEF - CCFM - UFPR. lucasflorestal@yahoo.com.br

${ }^{2}$ Dr. Nat. Tech., Professor do Departamento de Ciências Florestais, CCR, UFSM. schuma@ccr.ufsm.br

${ }^{3}$ Acadêmicos do curso de Engenharia Florestal - CCR - UFSM.

${ }^{4}$ Engenheira Florestal. marienoya@yahoo.com.br
} 
No manejo da vegetação de sub-bosque de um povoamento florestal, vários aspectos devem ser levados em conta, pois se por um lado sua manutenção traz alguns benefícios, como diminuição da incidência de radiação solar no solo e, conseqüentemente a retenção da umidade no solo, por outro, relacionado ao aspecto da proteção florestal, trata-se de um veículo de propagação rápida de incêndios para a copa das árvores, principalmente em caso de povoamento jovens, como é o caso em que a altura média da vegetação de sub-bosque ultrapassa inclusive a altura do primeiro galho da copa da árvore. (Pippi et al., 2000).

Countryman apud Ribeiro (1998), cita os principais atributos do material combustível: a continuidade, o arranjo e a quantidade. As características ligadas ao processo da ignição são a geometria das partículas, a textura da superfície, o conteúdo de umidade, a composição química e a absorção térmica.

Um estudo que envolva o uso atual da terra (material combustível), condições topográficas e exposição do terreno, malha viária, entre outros, pode auxiliar na detecção de locais que apresentam maior risco de ocorrência de incêndios, o que facilita $o$ planejamento e as estratégias de prevenção e combate (Couto e Cândido, 1992).

O Platanus $x$ acerifolia é uma árvore lenhosa de porte avantajado, podendo atingir aos 25 anos de idade, 25 metros de altura e 40 $\mathrm{cm}$ no DAP. É uma espécie intolerante, isto é, cresce muito bem em luminosidade total, muito adaptada às baixas temperaturas, resistente à seca, porém sensível às altas temperaturas, desenvolvendo-se muito bem em climas temperados e temperados frio (Harlow \& Harrar, 1969). Sua madeira é utilizada para os mais variados fins e vem se destacando na fabricação de móveis, especialmente móveis vergados à semelhança do açoita-cavalo (Luehea divaricata).

Este trabalho teve o objetivo de quantificar o material combustível existente no sub-bosque de um povoamento de Platanus $x$ acerifolia.

\section{MATERIAIS E MÉTODOS}

O presente trabalho foi desenvolvido durante os meses de novembro e dezembro de 2003 e janeiro de 2004, em um povoamento esperimental de Platanus $x$ acerifolia instalado em junho de 1999, na Universidade Federal de Santa Maria, em área a 90 metros de altitude, situada entre os paralelos $29^{\circ} 43^{\prime} 57^{\prime \prime}$ e $29^{\circ} 55^{\prime}$ $30^{\prime \prime}$ de latitude Sul e entre os meridianos $53^{\circ}$ 42 ' 13 " e $53^{\circ} 48^{\prime} 02^{\prime \prime}$ de longitude oeste de Greenwich.. As etapas de secagem das amostras e pesagem das mesmas foram efetuada no Laboratório de Ecologia Florestal, no Centro de Ciências Rurais, UFSM.

$\mathrm{O}$ solo da área pertence à Unidade de Mapeamento Santa Maria, com textura média, relevo suavemente ondulado e substrato síltico-arenito. São solos medianamente profundos, com cores bruno acinzentadas no horizonte A e bruno amareladas no horizonte B, friáveis e imperfeitamente drenados (Brasil, 1973).

O povoamento instalado trata-se de um teste para identificar o melhor espaçamento para a condução de um povoamento da espécie. Foram testados os espaçamentos $\mathrm{T} 1=$ $3 \times 2 \mathrm{~m}, \mathrm{~T} 2=3 \times 3 \mathrm{~m}$ e T3$=3 \times 4 \mathrm{~m}$, em três blocos, com três repetições, constituindo nove parcelas amostrais de 18 x $30 \mathrm{~m}$. Por conseguinte, em cada parcela foi instalada uma unidade amostral de levantamento de biomassa total do sub-bosque, constituindo, dessa forma, três repetições de quantificação de biomassa por tratamento de espaçamento.

A parcela constituiu-se de um quadrado com $4 \mathrm{~m}^{2}$ de área, onde a vegetação existente teve a altura média medida e foi classificada em três classes de diâmetro $(0,25$; 1,$0 ; 3,0$ polegadas) com o auxílio de um gabarito (Figura 1). Após a classificação, foi cortada ao nível do solo, pesada com balança de gancho e dela retirada uma amostra de cada classe de diâmetro para a determinação do percentual de umidade em laboratório, com secagem em estufa a $75^{\circ} \mathrm{C}$ por três dias.

Os dados obtidos foram analisados estatisticamente por comparação de médias, a $95 \%$ de confiabilidade. 


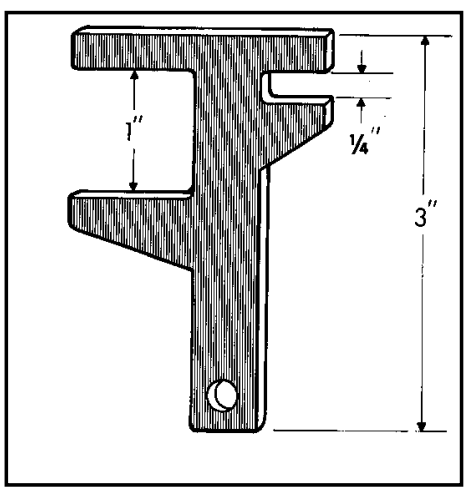

Figura 1: Gabarito para classificação da biomassa no sub-bosque nas diferentes classes de diâmetro

Figure 1: Answer sheet for classification of the biomass in the sub-forest in the different diameter classes

\section{RESULTADOS E DISCUSSÃO}

Observou-se que o sub-bosque do povoamento avaliado não apresentava vegetação com diâmetro igual ou superior a 3 polegadas, provavelmente em função do terreno apresentar-se bastante alagadiço, impedindo a instalação de espécies de maior porte.

A classe de diâmetro intermediária $(0,25-1,00$ polegadas $)$ constituiu-se unicamente de uma espécie, a vassoura (Baccharis sp.), que atingiu altura máxima de $2,5 \mathrm{~m}$ e altura média de $1,5 \mathrm{~m}$. A classe inferior $(0-0,25$ polegadas $)$ continha algumas bromeliáceas e gramíneas adaptadas a condições de hidromorfia (excesso d'água), como Herianthum sp. e o capim cortadéria, com portes diferenciados, não ultrapassando $1 \mathrm{~m}$ de altura.

$\mathrm{Na}$ Tabela 1 são apresentadas as médias de biomassa seca para as diferentes classes de diâmetro nos respectivos tratamentos, discriminadas pelo método de comparação de médias.

Tabela 1: Biomassa média $\left(\mathrm{mg} \cdot \mathrm{ha}^{-1}\right)$ por classe de diâmetro. Letras iguais na vertical identificam valores estatisticamente iguais pelo método de comparação de médias, a 95\% de confiabilidade

Table 1: Average biomass (mg.ha-1) for diameter classes. Equal letters in the vertical identify statistcly equal values for the method of comparison of averages, $95 \%$ of trustworthiness

\begin{tabular}{ccc}
\hline \multirow{2}{*}{ Tratamento } & \multicolumn{2}{c}{ Quantidade média de biomassa seca (mg/ha) } \\
\cline { 2 - 3 } & Diâmetro 0,25 polegada & Diâmetro 1,0 polegada \\
\hline T1 & $8,208 \mathrm{~A}$ & $1,697 \mathrm{~B}$ \\
$\mathrm{~T} 2$ & $9,061 \mathrm{~A}$ & $1,389 \mathrm{~B}$ \\
$\mathrm{~T} 3$ & $7,987 \mathrm{~A}$ & $1,471 \mathrm{~B}$ \\
\hline
\end{tabular}

Tukey (a 95\% de confiabilidade). 


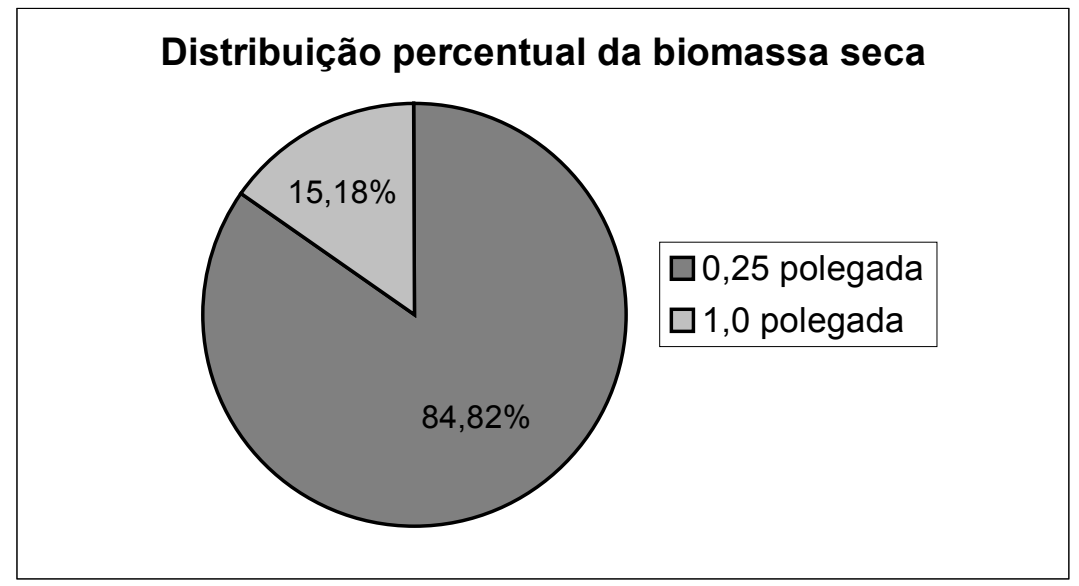

Figura 2: Distribuição percentual de biomassa para os diâmetros de 0,25 e 1,0 polegada.

Figure 2: Percentile distribution of biomass for diameters of the 0,25 and 1,0 inch.

A distribuição percentual dos valores médios de biomassa para as duas classes avaliadas pode ser observado na figura 2 .

Para Eucalyptus viminallis, foi encontrado, na quantificação de material combustível no sub-bosque de um povoamento com 13 anos de idade, valor médio de 27,0 mg.ha ${ }^{-1}$ na classe até $0,6 \mathrm{~cm}$ de diâmetro, correspondendo a $95 \%$ do total de material combustível inventariado (Ribeiro e Soares, 1998). Pode-se observar uma grande disparidade desse valor com o encontrado neste estudo, igual a $8,42 \mathrm{mg} \cdot \mathrm{ha}^{-1}$ na primeira classe $(0,25$ polegada $=0,625 \mathrm{~cm})$, equivalente a $85 \%$ do total. Pode-se supor que tal fato deve-se ao elevado grau hidromórfico do terreno onde encontra-se instalado o povoamento de plátano avaliado. Com relação à distribuição da biomassa combustível na classe inferior, observa-se semelhança entre os valores percentuais. Van Loon (1969), para Eucalyptus pilularis, encontrou $84 \%$ do material combustível inventariado presente na primeira classe $(0-0,6 \mathrm{~cm})$.

Em estudos com Pinus elliotti, Pippi et al. (2000), encontraram aproximadamente 17 mg.ha ${ }^{-1}$ de material combustível seco no subbosque, com até 1 polegada de diâmetro, dado também superior ao encontrado neste estudo.

\section{CONCLUSÃO}

O perigo de incêndios em florestas, sejam elas plantadas ou nativas, é constante nos povoamentos, entretanto podem ser tomadas algumas medidas para diminuir a possibilidade de ocorrência ou ainda a intensidade do mesmo, caso venha a ocorrer.

$\mathrm{O}$ povoamento avaliado não apresentou taxas elevadas de material combustível no sub-bosque, provavelmente pelo elevado grau de hidromorfismo do solo da área, que apresenta aspecto de banhado, diminuindo a variedade de plantas componentes do sub-bosque, bem como sua densidade.

Convém salientar que o sub-bosque contém exemplares de plantas com alturas elevadas, por vezes superando a altura média do povoamento, assim como grande número de plantas secas, fatos esses que, aliados a dias com elevadas temperaturas e baixa umidade, podem ocasionar incêndios de grandes proporções. Dessa forma, é aconselhado para a área, roçadas periódicas, procurando diminuir a quantidade e a altura das plantas.

\section{REFERÊNCIAS}

BRASIL. Ministério da Agricultura. Divisão de Pesquisa Pedológica DNPEA. Levantamento de reconhecimento dos solos do Estado do Rio Grande do Sul. Recife, 1973. 431p. (Boletim Técnico, 30).

COUTO, E.A.; CANDIDO, J.F. Incêndios florestais. Imprensa Universitária - UFV, Viçosa, MG, 1992. 101p.

HARLOW, W. M.; HARRAR, E. S. Textbook of Dendrology. Library of Congress, Catalog Card Number 68 - 17188, New York, $5^{\text {a }}$ Edition, 1969, 512p. 
PIPPI, M. C.; KRIEGER, J. M.; HOPPE, J. M. Quantificação do material combustível na serrapilheira e vegetação de sub-bosque e inventário florestal de uma floresta de Pinus elliotti aos 9 anos. Anais do $8^{\circ}$ Congresso Florestal Estadual de Nova Prata. Nova Prata, RS, 2000. CD ROOM.

RIBEIRO, G. A.; SOARES, R.V. Caracterização do material combustível superficial e efeitos da queima controlada sobre sua redução em um povoamento de Eucalyptus viminallis. Revista Cerne, V.4, N.1, p.057-072, 1998. Lavras, UFLA, 1998.
SANTANA, C. A.; SCHUMACHER, M. V.; HOPPE, J. M.; BARBIERI, S. J.; CECONI, D. E. Quantificação do material combustível e dos nutrientes em um povoamento de Pinus taeda. CD Rom... $1^{\circ}$ Simpósio de Pós-graduação em Engenharia Florestal. Santa Maria, RS, 21 - 23 de novembro, 2001, p.373 - 381 .

SOARES, R. V. Ocorrência de incêndios em povoamentos florestais. Floresta. $\mathrm{n}^{0} 22$. Curitiba: Imprensa Universitária, 1994. p.3953.

VAN LOON, A.P. Investigations into the effects of prescribed burning on young evenaged blackbutt. New South Wales : Forestry Comission of New South Wales, 1969. 49 p. (Research Note, n. 23). 